\title{
Influence of sprinkler irrigation droplet diameter, application intensity and specific power on flower damage
}

\author{
Yisheng ZHANG ${ }^{1}$, Delan ZHU (凶) $)^{1,2}$ \\ 1 College of Water Resources and Architectural Engineering, Northwest A\&F University, Yangling 712100, China \\ 2 Institute of Water-saving Agriculture in Arid Areas of China, Northwest A\&F University, Yangling 712100, China
}

\begin{abstract}
To determine the main parameters of droplet strike damage and avoid flower injury due to the unsuitable practices during sprinkler irrigation, an indoor experiment of irrigation droplet impact on cyclamen was conducted. The influences of different parameters such as droplet diameter, application intensity, specific power on flower strike damage was analyzed using Image Pro-Plus software to compute strike damage area and define damage level by sense-analysis. The results showed that a damage area of $<1 \%$ represents a safe irrigation level, $1 \%-3 \%$ slight damage level, 3\%-6\% moderate damage level, and $>6 \%$ heavy damage level. Equations of application intensity, specific power with sprinkler irrigation time and flower injury ratio were regressed against parameters which cause impact damages. The results indicated that specific power has a significant correlation with injury, and flower damage area increased as the increasing of the value of specific power for the same irrigation time. Application intensity was also correlated with injury when the droplet diameter was larger than $1 \mathrm{~mm}$. When the duration of sprinkler irrigation was 1, 5 and $10 \mathrm{~min}$, the threshold of impinging damage of application intensity was 25.30, 5.01 and $1.64 \mathrm{~mm} \cdot \mathrm{h}^{-1}$ and the specific power was $0.467 \times 10^{-3}$, $9.340 \times 10^{-3}$ and $3.110 \times 10^{-3} \mathrm{~W} \cdot \mathrm{m}^{-2}$. These results provide a reference for determining the suitable values of sprinkler properties in operation design.
\end{abstract}

Keywords application intensity, damage, floriculture, flowers, specific power, sprinkler irrigation

\section{Introduction}

With the development of sprinkler irrigation technology, operational intelligence and precision have become a focus for future developments ${ }^{[1]}$. In most cases, flowers are

Received December 15, 2016; accepted April 4, 2017

Correspondence: dlzhu@126.com grown in greenhouses and require high temperature and humidity, and sprinkler irrigation is beneficial for improving both temperature and humidity in greenhouse microclimates. Consequently, this kind of irrigation has been broadly applied in floriculture. However, flowers are environmentally sensitive and can be easily damaged by external force. Thus, during the sprinkler irrigation, when scattered droplets fall on plant surfaces with a specific impulse force, the impact can be readily observed. When the impulse force of the droplet is too large during flowering, some area of the petals may die. When this dead area is large enough, the marketability will definitely be affected. Thus, studying the effects of sprinkler irrigation on flower health is of great practical importance.

In field experiments, Jin et al. ${ }^{[2]}$ studied the yield and structure of millet, mung beans, amaranth, cabbage and other crops under different sprinkler irrigation droplet sizes, and determined the suitable droplet diameters for these crops. Also, Yan et al. ${ }^{[3]}$ reported that small diameter water droplets reduce collision damage on crops. In recent years, most researchers have focused on studying sprinkler uniformity ${ }^{[4-7]}$ and the effects of environmental changes under the sprinkler irrigation on crop growth ${ }^{[8,9]}$. However, the collision damage to crops by water droplet has received little attention. The reasons for this might be that collision damage parameters for different plant types are difficult to determine and also quantifying the damage level, sprinkler technology elements (e.g., droplet diameter), sprinkler strength and kinetic energy strength is difficult. The main factors causing damage to crops are still unclear. Thus, from the perspective of safe irrigation, it is necessary to study the effects of irrigation droplets on different crops, to analyze the main factors that relate to the damage and to determine the suitable parameters for irrigation technology.

Compared with many other flowers, cyclamen has the advantages of a long flowering period and strong resistance to the strike of falling droplets, so is widely planted in China. Therefore, it is an ideal subject for the study of the main parameters for flower irrigation. By determining the ratio of petal damage under different sprinkler intensities, 
the flower damage levels were quantified, and the main parameters leading to the damage of flower determined to provide technical guidance for safe sprinkler irrigation.

\section{Materials and methods}

\subsection{Experimental setup}

The experiment was carried out in the hydraulics experiment hall of the Institute of Water-saving Agriculture in Arid Areas of China, Northwest A\&F University, Yangling 712100, Shaanxi Province, China, Using a Nelson D3000 spray head with blue concave plate and nozzle \#24 (4.76 mm in diameter; Nelson Irrigation Corporation, Walla Walla, WA, USA). The experimental setup and equipment included water tanks, pumps, flow meters (EMF5000-type electromagnetic flow meter, range from 0.2895 to $28.95 \mathrm{~m}^{3} \cdot \mathrm{h}^{-1}$, Shanghai Fan Yang Mechanical and Electrical Co. Ltd.), nozzle bracket, pressure gauges (0.4 grade precision pressure gauge, Xi'an Xiyi Co. Ltd.), gauge rain tube (HOBO-RG3-M type, onset computer Co. Ltd.) and two-dimensional video disdrometer (2DVD, Joanneum Research, Graz, Austria) ${ }^{[10]}$. Container-grown flowers were used, flower age was 1 year, average height was $250 \mathrm{~mm}$, all the flowers were supplied by Northwest Agriculture \& Forestry Science and Technology Development Co. Ltd., Yangling, Shaanxi Province.

\subsection{Data collection}

Application intensity: HOBO RG3-M-type self-recording rain barrels $( \pm 1 \%$ accuracy, $0.02 \mathrm{~mm}$ resolution, $257 \mathrm{~mm}$ tube high, $15.2 \mathrm{~mm}$ ID) were used to collect irrigation water, barrels were aligned to the jet with a layout spacing of $1 \mathrm{~m}$. To obtain a complete single beam water and energy distribution in the sprinkler coverage area, the measuring points were widened and narrowed, and the test time was $1 \mathrm{~h}$. Droplet diameter and landing velocity: measurements of water droplet diameter and velocity were conducted by 2DVD, collection points were the same as the rain barrels and aligned to the jet direction when obtaining data. Data were simultaneously monitored by 2DVD. Petal condition: two days after the test, pictures of the petals were taken and processed through the Image-Processing Plus image software to determine damage area (petal damage proportion, PDP).

\subsection{Data analysis and testing point selection}

Calculation methods for droplet average diameter $\left(D_{v}\right)$ and specific power $(S p)$ were as follows.

$D_{v}$ in Table 1 was calculated using the volumetrically weighted average method ${ }^{[11]}$ :

$$
D_{v}=\frac{\sum_{i=1}^{n} d_{i}^{4}}{\sum_{i=1}^{n} d_{i}^{3}}
$$

where $D_{v}$ is droplet diameter of testing point (mm), $i$ is the index of an array of testing droplets, $d_{i}$ is the exact droplet diameter of testing droplets.

$S p$ was calculated using the following equation ${ }^{[12]}$ :

$$
S p=\left[\frac{\sum_{i=1}^{D_{n}} \frac{\rho_{w} d_{i}^{3} v_{2}^{2}}{12}}{1000 \sum_{i=1}^{D_{n}} \frac{\pi d_{i}^{3}}{6}}\right] \cdot \frac{R_{i}}{3600}
$$

where $S p$ is the specific power $\left(\mathrm{W} \cdot \mathrm{m}^{-2}\right), D_{n}$ is the total droplet number, $\rho_{w}$ is the water density $\left(\mathrm{kg} \cdot \mathrm{m}^{-3}\right), d_{i}$ is the diameter of the $i$ th droplet $(\mathrm{mm}), v_{i}$ is the velocity of the $i$ th droplet $\left(\mathrm{m} \cdot \mathrm{s}^{-1}\right), \pi$ is the circumference ratio, and $R_{i}$ is the water quantity of testing point $\left(\mathrm{mm} \cdot \mathrm{h}^{-1}\right)$.

First, the hydraulic characteristics of the sprinkler were tested, the sprinkler pressure head was set to $200 \mathrm{kPa}$ at $1.5 \mathrm{~m}$ relative height, and then the parameters of application intensity, droplet diameter and velocity, spraying distance were measured. Test results are given in Table 1. According to the test results, 10 test points were set as the strike damage points, i.e., 2.0, 5.0, 5.5, 6.0, 6.5, $7.0,7.5,8.0,8.5$ and $8.7 \mathrm{~m}$ from the nozzle center. The irrigation time was at five levels, 15, 30, 45, 60 and $120 \mathrm{~s}$, and the total target number to 50 .

\subsection{Data processing}

\subsubsection{Correlation analysis}

Data correlation analysis of application intensity, specific

\begin{tabular}{|c|c|c|c|c|c|c|c|c|c|c|c|c|c|}
\hline \multirow{2}{*}{$\begin{array}{l}\text { Hydraulic } \\
\text { characteristic }\end{array}$} & \multicolumn{13}{|c|}{ Distance from the center point $/ \mathrm{m}$} \\
\hline & 1.0 & 2.0 & 3.0 & 4.0 & 5.0 & 5.5 & 6.0 & 6.5 & 7.0 & 7.5 & 8.0 & 8.5 & 8.7 \\
\hline$D_{v} / \mathrm{mm}$ & 0.722 & 0.478 & 0.589 & 0.811 & 1.114 & 1.252 & 1.428 & 1.542 & 1.771 & 2.095 & 2.701 & 3.197 & 3.367 \\
\hline$R /\left(\mathrm{mm} \cdot \mathrm{h}^{-1}\right)$ & 1.2 & 0.2 & 0.4 & 1.2 & 6.8 & 10.8 & 12.4 & 23.2 & 44 & 67.2 & 26.8 & 9.2 & 0.4 \\
\hline$S p /\left(\mathrm{W} \cdot \mathrm{m}^{-2}\right)$ & 0.0012 & 0.0001 & 0.0003 & 0.0017 & 0.0154 & 0.0287 & 0.0384 & 0.0812 & 0.1817 & 0.3371 & 0.1694 & 0.0658 & 0.0030 \\
\hline
\end{tabular}

Table 1 Hydraulic characteristics of Nelson D3000 type sprinkler head 
power and petal damage proportion using SPSS 16.0 software.

\subsubsection{Curve fitting}

The analysis of different irrigation times and the relationship between application rate and PDP were regressed using curve fitting software, 1stOpt (http://7d-soft.com).

\section{Results}

As shown in Fig. 1, flower morphology will be damaged during sprinkler irrigation at some setting point, and the quality of the blooms will also be greatly reduced as the number of crushed flowers is increased. And the factors of hydraulic characteristic that causes damage to the flowers should be analyzed, and before do these things, the flower damage quantization and damage levels should be established.

\subsection{Classification of degrees of petal strike damage}

Figure 2 shows examples of petal damage with the damage (a)

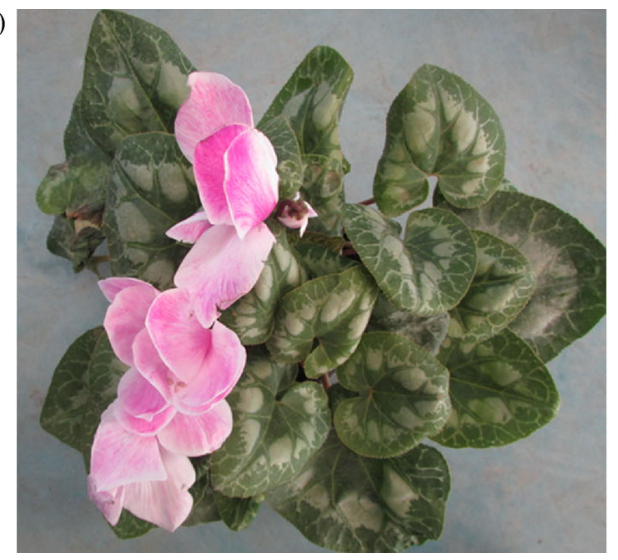

proportion in a-g from small to large: $0.55 \%, 1.02 \%$, $1.93 \%, 2.87 \%, 4.13 \%, 5.96 \%$ and $9.66 \%$, respectively. Strike damage was classified through sense evaluation. From Fig. 2, it can be concluded that when the damage proportion is $<1 \%$ (Fig. 2a), droplets have no effect on the ornamental character. However, when the damage proportion ranged from $1 \%$ to $3 \%$ (Fig. 2c, Fig. 2d) there was a definite effect on the ornamental character, from $3 \%$ to $6 \%$ (Fig. 2e, Fig. 2f) a significant effect, and $>6 \%$ (Fig. 2g) a drastic effect. Therefore, we define the strike damage area of $<1 \%$ as a safe level of sprinkler irrigation, $1 \%$ to $3 \%$ as slight damage, $3 \%$ to $6 \%$ as moderate damage and $>6 \%$ as heavy damage. Also, it can be seen in Fig. 2, that there was no apparent pattern of wound area after strike damage because the petals were overlapping, which resulted in different exposure to strike damage for different petals.

3.2 Effect of water droplet diameter on the petal damage proportion

Figure 3 shows the relationship between droplet diameter and damage proportion for different irrigation times. From Fig. 3, it can be seen that the range of flower damage increased with the increase in irrigation time. Under

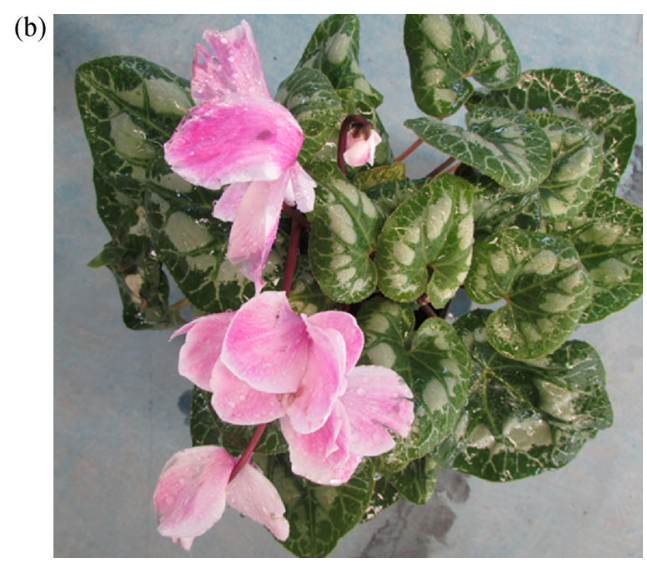

Fig. 1 Changes in flower morphology before (a) and after (b) sprinkler irrigation (a)

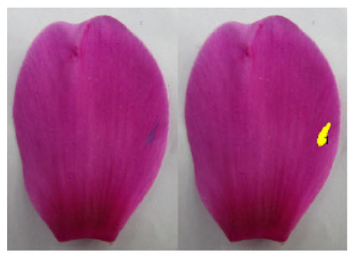

(b)

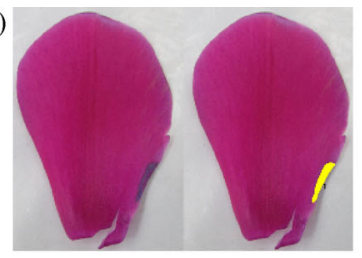

(f)

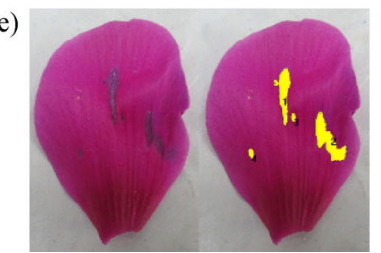

(c)

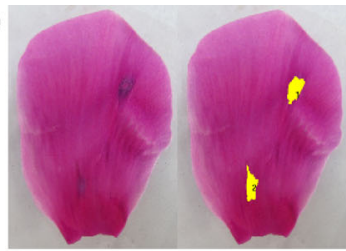

(d)

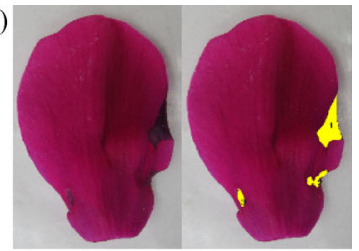

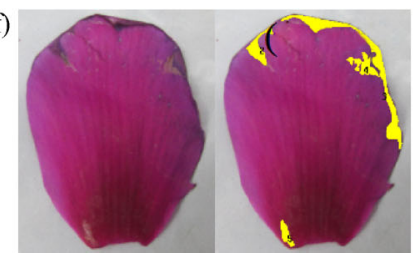

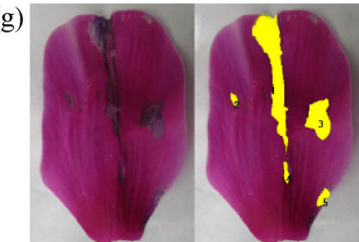

Fig. 2 Different proportions of strike damage to petals. (a) $0.55 \%$; (b) $1.02 \%$; (c) $1.93 \%$; (d) $2.87 \%$; (e) $4.13 \%$; (f) $5.96 \%$; (g) $9.66 \%$. 


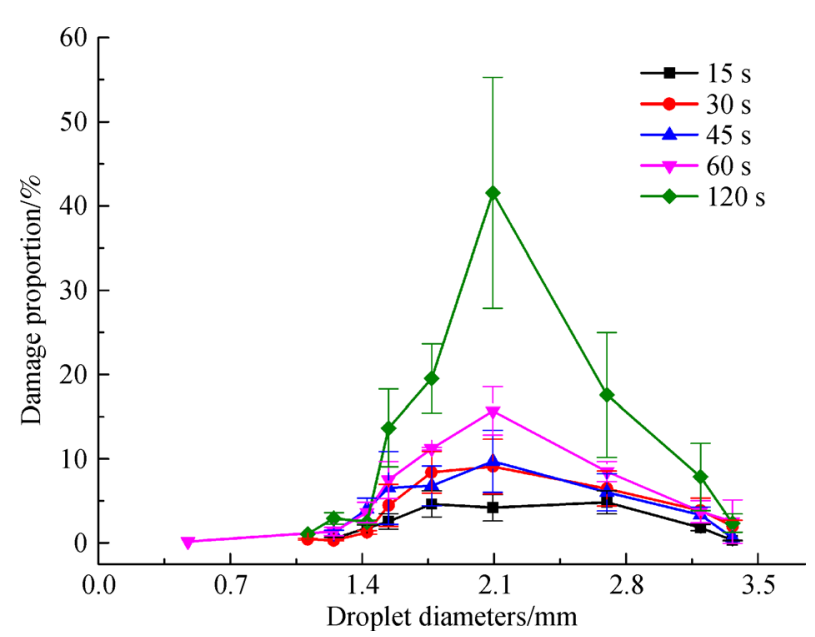

Fig. 3 Relationship between petal damage proportion and droplet diameter

different irrigation times from short to long: the damage proportion ranged from $0 \%-4.58 \%, 0 \%-9.03 \%, 0 \%-$ $9.66 \%, 0 \%-15.60 \%$ and $0 \%-41.50 \%$. For the same irrigation time, the strike damage proportion on flower petals increased with the increase in the droplet diameter at first and then decreased. With a longer irrigation period, this tendency was more noticeable. Figure 3 also shows that, there was less damage from small or very large droplets (over $3 \mathrm{~mm}$ ) and when the droplet diameter was $<1 \mathrm{~mm}$, the sprinkler irrigation appeared to cause no strike damage on flowers. However, it was found (Fig. 2) that with the increase in droplet diameter, the damage proportion decreased after peaking at $2.1 \mathrm{~mm}$ droplets. For the same diameter, the damage proportion increased with time. These results indicate that because the diameter of droplet near to the nozzle was small, the kinetic power was weak, and this was not evident in the flower strike diameter. While at the end of the jet, the diameter and kinetic power were the greatest, however these testing points have a small value in application intensity, the

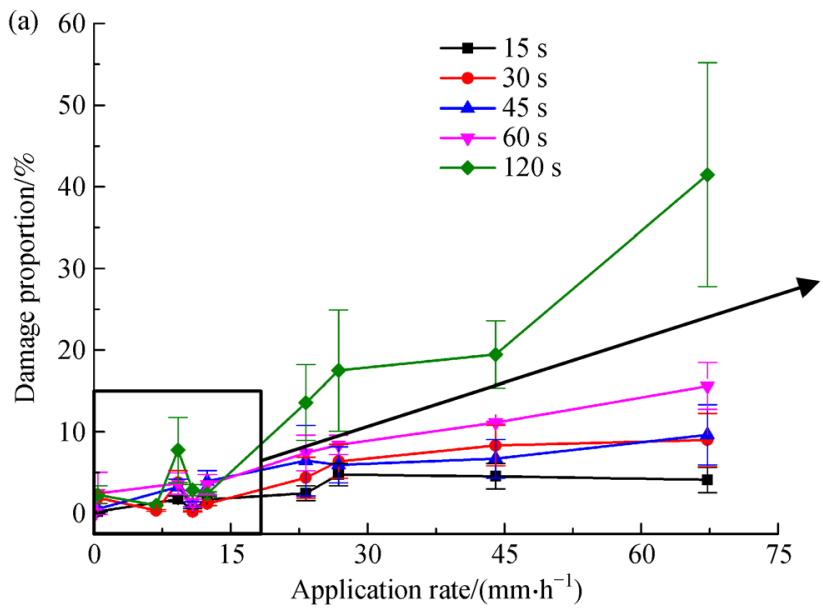

probability of getting hit was also low. From this point of view, using droplet diameter as an indicator for safe sprinkler irrigation has its limitations.

\subsection{Relationship between application intensity and damage proportion}

Figure 4 shows the relationship between application intensity and damage proportion for five different time periods. For the same sprinkler time, the damage proportion increased with the increase in application rate. For $15 \mathrm{~s}$ of irrigation, when application intensity was greater than $30 \mathrm{~mm} \cdot \mathrm{h}^{-1}$, the damage decreased slightly, which may be because with short times the application intensity did not reach the threshold value. With longer irrigation times, the linear relationship between application rate and damage proportion became apparent. Figure 4 also shows that, under different irrigation times for $9.2 \mathrm{~mm} \cdot \mathrm{h}^{-1}$, the proportion of damage increased because the testing points were located at the end of spray jet and the droplets hit the petal more heavily due to the larger droplet diameters. Based on these results, it can be concluded that a comparatively large application rate will certainly produce strike damage and it is reasonable to judge the safety of the irrigation by application rate. The testing point which is $5 \mathrm{~m}$ from the nozzle, the application rate was $6.8 \mathrm{~mm} \cdot \mathrm{h}^{-1}$, the damage proportion in this testing point was smaller than the point of $8.7 \mathrm{~m}$ from the nozzle, of which the application rate was $0.4 \mathrm{~mm} \cdot \mathrm{h}^{-1}$, the reason is that the droplets at $5 \mathrm{~m}$ is smaller than that at the end of the nozzle, and the impact force was relatively small, so it may also be limited as an indicator of safe sprinkler irrigation.

3.4 The relationship between specific power and proportion of petal damage

Specific power $(S p)$ refers to the kinetic energy value under per unit area and per unit time of sprinkler irrigation ${ }^{[13]}$, which comprehensively reflects the irrigation intensity

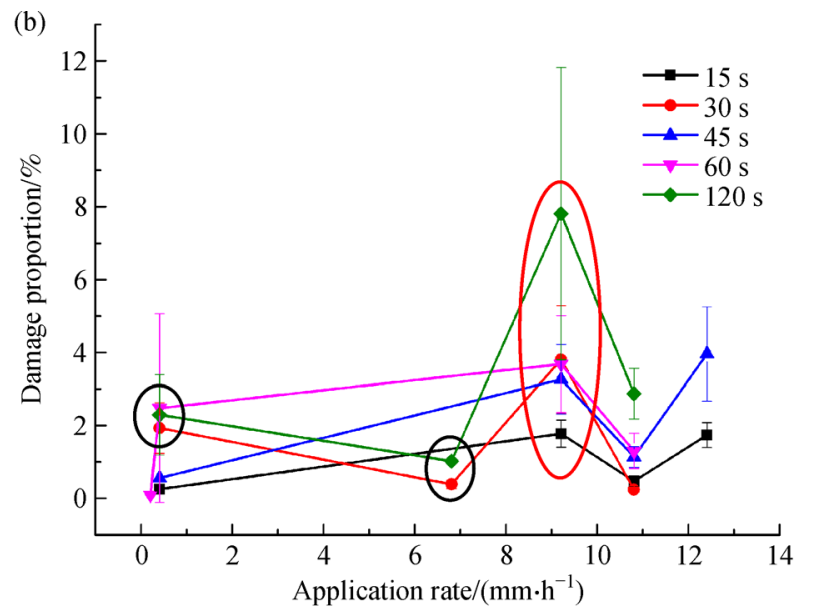

Fig. 4 Relationship between proportions of petal damage and application intensity 
water droplet diameter, water velocity, and other parameters. Figure 5 shows that petal damage proportion (PDP) increased with the increasing of $S p$. When the irrigation time was short, the linear relationship was weak, which was quite similar to the relationship between application rate and PDP. To determine the main parameters causing the strike damage, SPSS software was used for analyzing the relationship, and from the perspective of safe irrigation, selecting the greatest petal damage proportion for each sample as a target (Table 2). The regression coefficient of $S p$ was generally higher than application rate, except for when the sprinkling duration was $45 \mathrm{~s}$, illustrating that $S p$ and PDP are closely related. Thus, $S p$ is recommendedas an indicator for safe sprinkler irrigation.

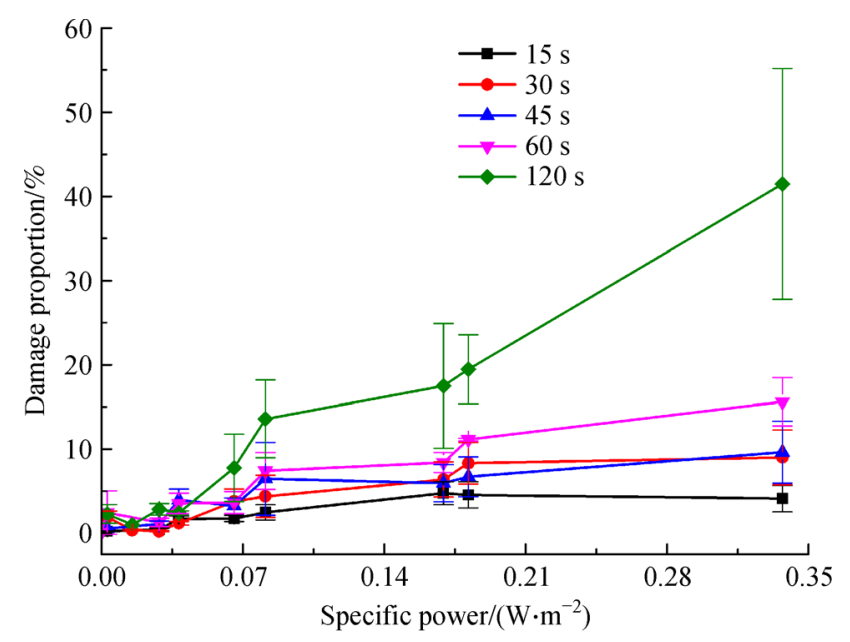

Fig. 5 Relationship between proportion of petal damage and specific power

\subsection{Analysis of the suitability of indicators for safe sprinkler} irrigation of cyclamen

Commonly, if the irrigation time is different, the impact (power) on the petals from droplet strike will also be different. The power can be calculated by:

$$
W=S p \times T
$$

where $W$ is the power of sprinkler droplet per unit of area $\left(\mathrm{J} \cdot \mathrm{m}^{-2}\right), S p$ is the specific power $\left(\mathrm{W} \cdot \mathrm{m}^{-2}\right)$, and $T$ is the sprinkling time (s).

The relationship between $S$ and $W$ is obtained by calculation with the linear equation for $S$ and $W$ regressed by SPSS:

$$
S=m W+n R^{2}=0.942
$$

where $S$ is the value of PDP, and $m$ and $n$ are coefficients with $m=9.14 \times 10^{-3}$ and $n=5.74 \times 10^{-3}$.

From Eqs. (3) and (4), the equation for $S$ is:

$$
S=m S p \times T+n
$$

From Eq. (5), if parameters $S p$ and PDP are given, the secure irrigation time can be computed. Determination of the diameters and velocities of irrigation droplets requires a professional measurement instrument. Due to constrains of test conditions, the hydraulic characteristics are difficult for farmers to determine. The parameter $S p$ combines factors. Although $S p$ was a highly persuasive and sound indicator, using it to design irrigation is rather impractical. From the perspective of testing results, using application rate may not as suitable as $S p$, although it is still useful as a practical indicator for safe sprinkler irrigation. Through the analysis of different irrigation time, the relationship between application rate and PDP was regressed using curve fitting software, 1stOpt:

$$
S=a P^{b} T^{c}
$$

where $S$ is the value of PDP, $P$ is application intensity, $T$ is irrigation time, and $a, b$ and $c$ are coefficients with $a=$ $2.93 \times 10^{-5}, b=1.043$ and $c=1.061$.

Applying root mean square error (RMSE) as an indicator of accuracy, the equation is:

$$
\mathrm{RMSE}=\sqrt{\frac{1}{N} \sum\left(D-D_{m}\right)^{2}}
$$

where $D$ is the calculated PDP, $D_{m}$ is the tested PDP, $N$ is the measurement sample number (in this case $N=50$ ).

Figure 6 shows that RMSE was 0.0197 and $R^{2}=0.925$. This indicates that the calculated values and tested values fitted closely around the identity line, indicating that the accuracy of the regressed equation was high. Thus, it is applicable for calculating the safe $P$ value under various periods of time.

During the sprinkler irrigation of cyclamen, reasonable working condition should be selected in order to avoiding damage to the petals. When designing sprinkler irrigation system to irrigate flowers, and the sprinkler hydraulic parameters such as specific power $(S p)$ and irrigation intensity were given, we should take parameters of $S p$ into consideration preferentially in the process of designing. In general, $S p$ of the sprinkler is difficult to obtain and in this

Table 2 Coefficients of application intensity and specific power

\begin{tabular}{lccccc}
\hline \multirow{2}{*}{ Analysis indicator } & \multicolumn{4}{c}{ Sprinkler irrigation time/s } \\
\cline { 2 - 6 } & 15 & 30 & 45 & 60 & 120 \\
\hline Application rate & $0.827^{* *}$ & $0.901^{* *}$ & $0.915^{* *}$ & $0.963^{* *}$ & $0.968^{* *}$ \\
$S p$ & $0.853^{* *}$ & $0.922^{* *}$ & $0.905^{* *}$ & $0.961^{* *}$ & $0.987^{* *}$ \\
\hline
\end{tabular}

Note: **, $P<0.01, n=10$. 


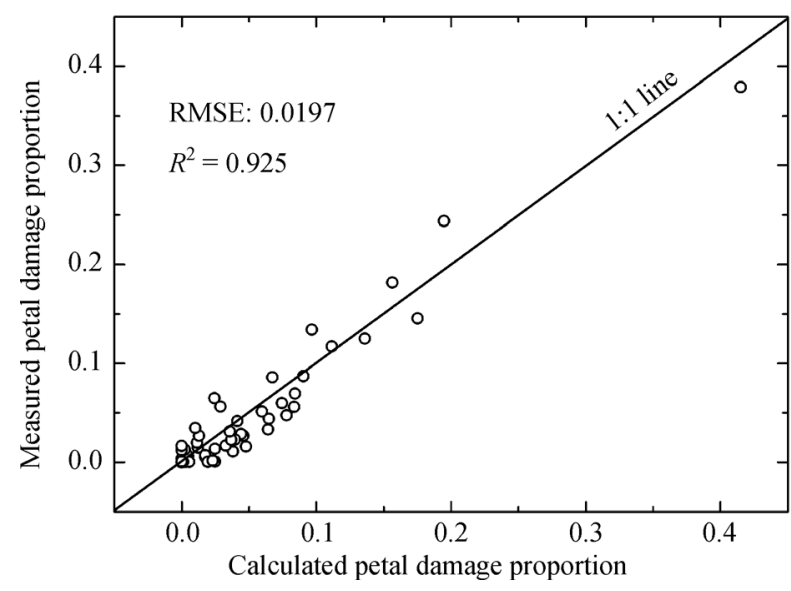

Fig. 6 Relationship between calculated and measured proportion of petal damage

case the irrigation intensity can be chosen when designing the sprinkler irrigation system. Table 3 and Table 4 shows the threshold value of irrigation intensity and $S p$ with various damage levels calculated by Eq. (6) and Eq. (5), respectively. For the sprinkler irrigation system, irrigation time and irrigation parameters can be designed based on these two table, and for a movable sprinkler irrigation system, the moving speed can be set so as to avoid petal damage.

\section{Discussion}

At present, mobile sprinkler irrigation machines are mostly equipped with a spray plate sprinkler whose application intensity is controlled by nozzle type, nozzle model, working pressure head and other factors ${ }^{[14-16]}$. Jet flow velocity of the rotating spray plate sprinkler nozzle is large and fragmentation insufficient resulting in both heavy impact and serious strike damage. For non-rotating spray plate sprinklers, the impact jet tongue is relatively small, and instantaneous peak irrigation intensity value is no more than $200 \mathrm{~mm} \cdot \mathrm{h}^{-1[17]}$. Under calm conditions, the peak area is generally smaller than $1 \mathrm{~m} \times 0.5 \mathrm{~m}$, if the additive effects of a multi-sprinkler are ignored, the peak application intensity is $50 \mathrm{~mm} \cdot \mathrm{h}^{-1}$ and peak transit is $1 \mathrm{~m}$ $\times 0.5 \mathrm{~m}$. If PDP is set as smaller than $1 \%$ as a safe irrigation standard and the safe irrigation time is $31 \mathrm{~s}$, then the movement speed of the sprinkler machine should not be less than $58 \mathrm{~m} \cdot \mathrm{h}^{-1}$. If the peak application intensity of the selected nozzle is lower, then the speed might be slower as well. For impact sprinklers, the diameter of droplet is generally greater than $2 \mathrm{~mm}$ under normal operating conditions $^{[2,18]}$, and the maximum $P$ value is less than $30 \mathrm{~mm} \cdot \mathrm{h}^{-1[19]}$, from Eq. (3) it is clear that the safe irrigation time should be not more than $52 \mathrm{~s}$. From the test results there was no influence in flower appearance when the droplet diameter was less than $1 \mathrm{~mm}$. Therefore, it is beneficial in floriculture to use nozzles with a higher atomization for sprinkler irrigation, however the effect of sprinkler irrigation on plants other than cyclamen needs to be investigated.

The extent of the level flower damage has not yet studied in recent years, and ornamental character is more of a subjective concern which varies with each individual. In this paper, the damage level was assessed by the observation of 12 graduate students, leading to the conclusion that damage area of $<1 \%$ represents safe irrigation level, 1\%-3\% slight damage level, 3\%-6\% moderate damage level, and $>6 \%$ heavy damage level.

\section{Conclusions}

The petal damage proportion of cyclamen flowers caused by spray water droplets under different conditions calculated by image processing software was determined by sensory evaluation. We define the strike damage area

Table 3 Threshold value of irrigation intensity with various damage levels at different irrigation time

\begin{tabular}{lrrrrrr}
\hline Damage level/\% & \multicolumn{5}{c}{ Irrigation intensity $/\left(\mathrm{mm} \cdot \mathrm{h}^{-1}\right)$} \\
\cline { 2 - 7 } & $1 \mathrm{~min}$ & $2 \mathrm{~min}$ & $3 \mathrm{~min}$ & $5 \mathrm{~min}$ & $10 \mathrm{~min}$ & $15 \mathrm{~min}$ \\
\hline 1 & 25.77 & 12.73 & 8.43 & 5.01 & 2.48 & 1.64 \\
6 & 73.88 & 36.50 & 24.16 & 14.37 & 7.10 & 13.80 \\
\hline
\end{tabular}

Table 4 Threshold value of specific power at various damage levels at different irrigation time

\begin{tabular}{|c|c|c|c|c|c|c|}
\hline \multirow{2}{*}{ Damage level/\% } & \multicolumn{6}{|c|}{ Specific power $/\left(\times 10^{-3} \mathrm{~W} \cdot \mathrm{m}^{-2}\right)$} \\
\hline & $1 \mathrm{~min}$ & $2 \mathrm{~min}$ & $3 \mathrm{~min}$ & $5 \mathrm{~min}$ & $10 \mathrm{~min}$ & $15 \mathrm{~min}$ \\
\hline 1 & 46.71 & 23.36 & 15.57 & 9.34 & 4.67 & 3.11 \\
\hline 3 & 266.01 & 133.00 & 88.67 & 53.20 & 26.60 & 17.73 \\
\hline 6 & 594.96 & 297.48 & 198.32 & 118.99 & 59.50 & 39.66 \\
\hline
\end{tabular}


of $<1 \%$ as a safe level of sprinkler irrigation, $1 \%-3 \%$ as slight damage, $3 \%-6 \%$ as moderate damage and $>6 \%$ as heavy damage.

The parameters of specific power $(S p)$ and irrigation intensity of the sprinkler have a significant influence on the petal damage, whereas spray water droplet had little influence. As the $S p$ and irrigation intensity selected for the sprinkler were all given, the parameter of $S p$ should be preferentially taken into consideration when designing flower sprinkler irrigation systems. In general, $S p$ of the sprinkler is difficult to obtain and in this case the irrigation intensity can be chosen during the design of the sprinkler irrigation system.

The relationship between application intensity and damage proportion can be used to guide the safe irrigation of cyclamen. Irrigation time and irrigation parameters for the sprinkler irrigation system, can be designed based on this relationship, and for movable sprinkler irrigation systems, the speed can be setting so as to avoid petal damage.

Acknowledgements This work was financially supported by the National Science and Technology Program in Rural Areas during the Twelfth Fiveyear Plan Period (2015BAD22B01-02).

Compliance with ethics guidelines Yisheng Zhang and Delan Zhu declare that they have no conflicts of interest or financial conflicts to disclose.

This article does not contain any studies with human or animal subjects performed by any of the authors.

\section{References}

1. Li Z L, Zhao W J, Sun W, Fan Y. Application prospect of sprinkler irrigation technology in water-short areas of northern China. Transactions of the Chinese Society of Agricultural Engineering, 2012, 28(6): 1-6 (in Chinese)

2. Jin Z S, Zhou M Y, Cheng J L, Gong F H. Study on appropriate atomized indicater and allowable application rate in sprinkler irrigation. Journal of Yangzhou University: Agriculture and Life Sciences Edition, 1992, 13(3): 49-55 (in Chinese)

3. Yan H J, Xiao J W, Li W Y, Li Y C, Hou Y S. Droplet size distributions of low-pressure damping sprinklers used in centerpivot irrigation systems. Journal of Hydraulic Engineering, 2014, 45(4): 467-473 (in Chinese)

4. Ortíz J N, De Juan J A, Tarjuelo J M. Analysis of water application uniformity from a centre pivot irrigator and its effect on sugar beet (Beta vulgaris L.) yield. Biosystems Engineering, 2010, 105(3): 367-379
5. Ortiz J N, Tarjuelo J M, De Juan J A. Effects of two types of sprinklers and height in the irrigation of sugar beet with a centre pivot. Spanish Journal of Agricultural Research, 2012, 10(1): 251264

6. Sezen S M, Yazar A. Wheat yield response to line-source sprinkler irrigation in the arid Southeast Anatolia region of Turkey. Agricultural Water Management, 2006, 81(1-2): 59-76

7. Montazar A, Sadeghi M. Effects of applied water and sprinkler irrigation uniformity on alfalfa growth and hay yield. Agricultural Water Management, 2008, 95(11): 1279-1287

8. Kang Y, Liu H J, Liu S P, Lou J. Effect of sprinkler irrigation on field microclimate. In: Proceedings of the 2002 ASAE Annual International Meeting/XV, CIGR World Congress 2002, Chicago. St Joseph: American Society of Agricultural and Biological Engineers. 2002, 022285

9. Berkowitz G A, Gibbs M. Reduced osmotic potential effects on photosynthesis: identification of stromal acidification as a mediating factor. Plant Physiology, 1983, 71(4): 905-911

10. Kruger A, Witold F K. Tow-dimensional video disdrometer: a description. Journal of Atmospheric and Oceanic Technology, 2002, 19(5): 602-617

11. Hong X U, Gong S H, Jia R Q, Liu X A. Study on droplet size distribution of ZY sprinkler head. Journal of Hydraulic Engineering, 2010, 41(12): 1416-1422 (in Chinese)

12. King B A, Bjorneberg D L. Droplet kinetic energy of moving sprayplate center-pivot irrigation sprinklers. Transactions of the ASABE, 2012, 55(2): 505-512

13. Liu H J, Kang Y H. Effects of droplets kinetic energy on soil infiltration rate and surface runoff under sprinkler irrigation. Irrigation and Drainage, 2002, 21(2): 71-74

14. Zhang Y S, Zhu D L, Zhang L, Gong X H. Study on translocating speed and water distribution uniformity of lightweight lateral move irrigation system. Journal of Drainage \& Irrigation Machinery Engineering, 2014, 32(7): 625-630 (in Chinese)

15. Montero J, Martínez A, Valiente M, Tarjuelo J M. Analysis of water application costs with a centre pivot system for irrigation of crops in Spain. Irrigation Science, 2013, 31(3): 507-521

16. Yan H J, Jin H Z, Qian Y C. Characterizing center pivot irrigation with fixed spray plate sprinklers. Science China Technological Sciences, 2010, 53(5): 1398-1405

17. Sayyadi H, Nazemi A H, Sadraddini A A, Delirhasannia R. Characterising droplets and precipitation profiles of a fixed sprayplate sprinkler. Biosystems Engineering, 2014, 119(1): 13-24

18. Chen D, Wallender W W. Droplet size distribution and water application with low-pressure sprinklers. Transactions of the ASAE, 1985, 28(2): 0511-0516

19. Liu J, Yuan S, Li H, Zhu X. Combination uniformity improvement of impact sprinkler. Transactions of the Chinese Society of Agricultural Engineering, 2011, 27(7): 107-111 (in Chinese) 